\section{Addition to araneofauna of Andhra Pradesh, India: occurrence of three species of Argyrodes Simon, 1864 (Araneae: Theridiidae)}

\author{
S.M. Maqsood Javed ${ }^{1}$, C. Srinivasulu ${ }^{2} \&$ Farida \\ Tampal ${ }^{1}$
}

${ }^{1}$ World Wide Fund for Nature-India (WWF), APSO, Ho.No. 818, Castle Hills, Road No. 2, Near NMDC, Vijayanagar Colony, Hyderabad, Andhra Pradesh 500057, India

${ }^{2}$ Wildlife Biology Section, Department of Zoology, University College of Science, Osmania University, Hyderabad, Andhra Pradesh 500007, India

Email: ${ }^{2}$ hyd2masawa@gmail.com (corresponding author)

Spiders of the genus Argyrodes Simon, 1864 (commonly called Argyrodes or Silver Dew Drop Spiders) can exist in a variety of relationships with other spiders as commensals, kleptoparasites or predators - depending on factors such as relative size, morphology of host web, and host feeding rate (Wise 1982; Larcher \& Wise

Date of publication (online): 26 June 2010

Date of publication (print): 26 June 2010

ISSN 0974-7907 (online) | 0974-7893 (print)

Editor: Manju Siliwal

Manuscript details:

Ms \# 02194

Received 13 March 2009

Final revised received 20 January 2010

Finally accepted 15 May 2010

Citation: Javed, S.M.M., C. Srinivasulu \& F. Tampal (2010). Addition to araneofauna of Andhra Pradesh, India: occurrence of three species of Argyrodes Simon, 1864 (Araneae: Theridiidae). Journal of Threatened Taxa 2(6): 980-985

Copyright: () S.M. Maqsood Javed, C. Srinivasulu \& Farida Tampa 2010. Creative Commons Attribution 3.0 Unported License. JoTT allows unrestricted use of this article in any medium for non-profit purposes, reproduction and distribution by providing adequate credit to the authors and the source of publication.

Acknowledgements: The authors are very much thankful to Shri Hitesh Malhotra, IFS, Principal Chief Conservator of Forest (Wildlife) and Chief Wildlife Warden, Andhra Pradesh for constant support and encouragement. We express gratitude to Shri Anil Kumar V. Epur, Chairman, WWF-AP State Committee, Hyderabad and Shri Ravi Singh, Secretary General \& CEO, WWF-India, New Delhi for constant support and encouragement. We also express our thanks to Shri Jayesh Ranjan, IAS, Managing Directo and Shri P.V. Ramana Reddy, IFS, Executive Director, Andhra Pradesh Tourism Development Corporation, Hyderabad for constant support and permitting us to conduct biodiversity studies in APTDC Eco-tourism sites. CS thanks Prof. T. Tirupathi Rao, Vice Chancellor, Osmania University and the Head, Department of Zoology, Osmania University, Hyderabad for encouragement and facilities. Thanks to Dr. Bhargavi who read the first draft and provided valuable comments. Lastly, we would like to thank Mr. P.S.M. Srinivas, Manager Corporate for exploring new places and all the WWF-Staff of APSO, Hyderabad for their constant support and timely suggestions.

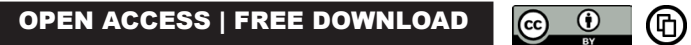

1985). Argyrodes may live in host webs without constructing any web of their own, but often they add fine lines between the spirals of an orb-web, and occasionally they live independently, making their own small theridiid webs (Exline \& Levi 1962). Fourteen species of the genus Argyrodes are known from India (Tikader 1966; Jose 2005; Siliwal \& Molur 2007), and so far no species of Argyrodes has been recorded from Andhra Pradesh. In Andhra Pradesh, the family Theridiidae is represented by Sri Lankan Black Widow Latrodectus erythromelas Schmidt \& Klaas, 1991.

Diagnosis of Argyrodes species is always a difficult task because of their minute size and variations within the same species from different localities. Thus many species have been resurrected by experts from time to time. According to Exline \& Levi (1962) almost all species of Argyrodes show some individual variation in color, with some specimens being darker (all, however, are silvery). There is also some variation in shape, slant and length of the male clypeal process. The genital plate of females does not appear to accumulate cuticle as the spider ages. Maybe to settle these lacunae Exline \& Levi (1962) carried out the revision and attempted to clarify the taxonomy of the genus Argyrodes. According to Chikuni (1989) the shape and coloration of the abdomen in Argyrodes is highly variable. Further, Agnarsson (2004) carried out morphological phylogeny and clarified that Argyrodes differs from other argyrodines by: lack of a functional triplet in the male, tight folding of the embolus and conductor, details of male carapace modifications, including median eyes on tubercles, details of life history (obligate kleptoparasitism), highly characteristic palpal organs, the theridiid tegular apophysis snug with a distinct cymbial apophysis, and embolus and conductor intertwined.

We have been studying spiders in Andhra Pradesh for the past decade, and over the past few months we have been observing and collecting interesting minute silver dew drop spiders. These spiders have been found hanging upside-down in the webs of Araneidae spiders, namely, Argiope anasuja, Cyrtophora citricola and Thelacantha brevispina. Through this paper, we report the occurrence of the genus Argyrodes Simon, 1864 for the first time in Andhra Pradesh, along with one species recorded for the first time from India and first report of three species from Andhra Pradesh. We also provide descriptions and a brief note on the natural history of all three species.

\section{Materials and Methods}

All measurements are given in millimeters and were made with digital dial calipers and ocular micrometer with 
up to $50 \mathrm{x}$ magnification with an error of $0.01 \mathrm{~mm}$ and rounded up to one significant decimal where appropriate. Photographs of live specimens were taken by Canon super macro digital camera, only minor color correction of the figures has been done; line diagrams were drawn with the help of a camera lucida attached to the stereomicroscope; epigyna were dissected and immersed in clove oil for $48 \mathrm{hr}$ to study internal structures. The collected specimens are preserved in $70 \%$ alcohol and deposited in the Natural History Museum of Osmania University, Hyderabad.

\section{Results}

We identified specimens belonging to three species including Argyrodes nephilae Taczanowski, 1872, Argyrodes argentatus O.P.-Cambridge, 1880 and Argyrodes falvescens O.P.-Cambridge, 1880. Argyrodes argentatus is widely distributed in the state of Andhra Pradesh (right from the coastal region to inland tracts), while Argyrodes nephilae and Argyrodes falvescens are, so far, known only from the single locality in Andhra Pradesh (Image 1). The characteristics of males and females of each species and notes on microhabitats are described below.

\section{Argyrodes nephilae Taczanowski, 1872 (Images 2 \& 3; Figures 1-3)}

\section{Material examined}

14.i.2009, 1 Male (NHM.OU.SPI.1-2009), 1 Female (NHM.OU.SPI.2-2009), $17^{\circ} 25^{\prime} \mathrm{N}$ \& $78^{\circ} 23^{\prime} \mathrm{E}$, along the avenue plantation of Gacchibowli road, Hyderabad, Andhra Pradesh, coll. S.M. Maqsood Javed.

\section{Description}

Male: Carapace black or dark brown above and below. Sternum is light brown. The basal joints of all the legs are white. The third and fourth legs are light colored, with a little brown colour at the ends of the joints. The second pair of legs are darker, and the first pair is almost black, except at the ends. Abdomen solid silver above with brownish patches laterally (in live condition, but turns solid silver after fixation in $70 \%$ ethyl alcohol). A dark brown median patch is present on the dorsal region and a small black spot at the tip. Ventral and lower parts of the abdomen and sides are almost black with a pair of round silvery spots in front of spinnerets. Cephalic projection bearing median eyes is raised. Clypeal projection slender, extending anteriorly at a slight upward angle beyond head, narrowed in middle and expanded into a knob distally (Figure 1). Abdomen is small in size and

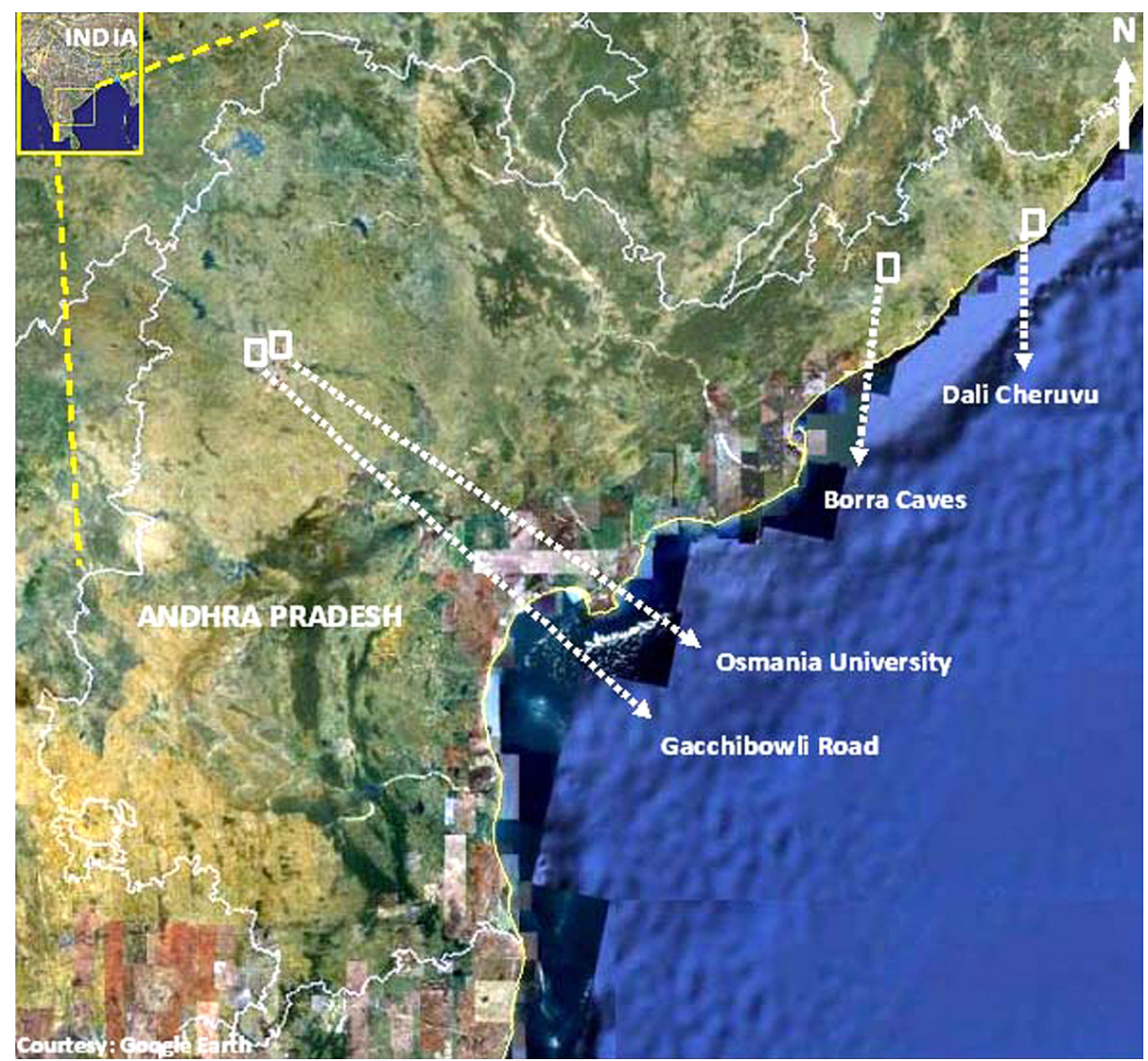

Image 1. Satellite image showing map (not to scale) depicting collection sites of Argyrodes spp. 

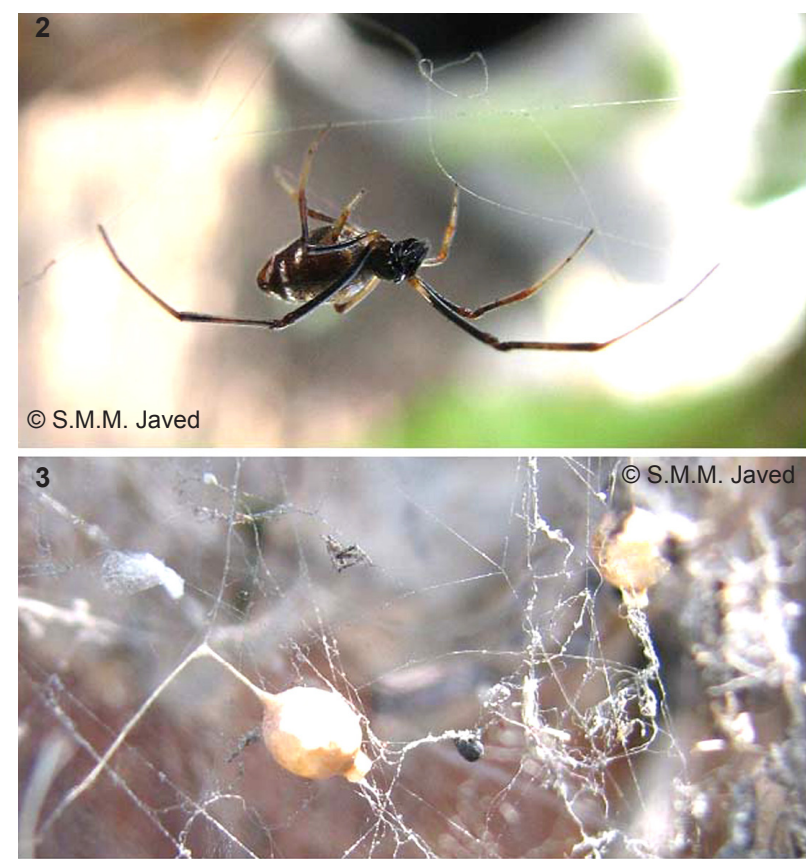

Images 2-3. 2 - Argyrodes nephilae female (live) hanging inverted on the web; 3 - Egg sac hanging inverted in the web.

silvery with dusky brown patches, cone-shaped abdomen. Palpal organ as shown in Figure 2.

Measurements: Total length 1.98; carapace 0.88 long, 0.58 wide; abdomen 1.10 long, 0.90 wide, height 1.68 .

Leg formula: 1,4,2,3; leg lengths: I,II,III,IV (3.99, 1.77, $1.30,2.56)$.

\section{Female}

Similar to males in coloration, but does not possess cephalic projection. They are comparatively larger in size than males (Image 2). Epigynum as shown in Figure 3.

Measurements: Total length 4.10; carapace 1.80 long, 0.76 wide; abdomen 2.30 long, 1.30 wide, height $3.02 \mathrm{~mm}$.

Leg formula: 1,4,2,3; leg lengths: I,II,III,IV (8.67, 5.12, $3.90,6.02)$.

\section{Distribution}

Central and southern Florida, West Indies, eastern South America, to Galapagos Islands (Exline \& Levi 1962). According to Platnick (2009) it is distributed in USA, West Indies to Argentina and Galapagos Islands. This is the first record of the species from India.

\section{Micro-habitat}

We recorded Argyrodes nephilae in the web of Araneidae spider Cyrtophora citricola on an avenue tree along the state highway stretch that passes through Gachibowli area of Hyderabad.

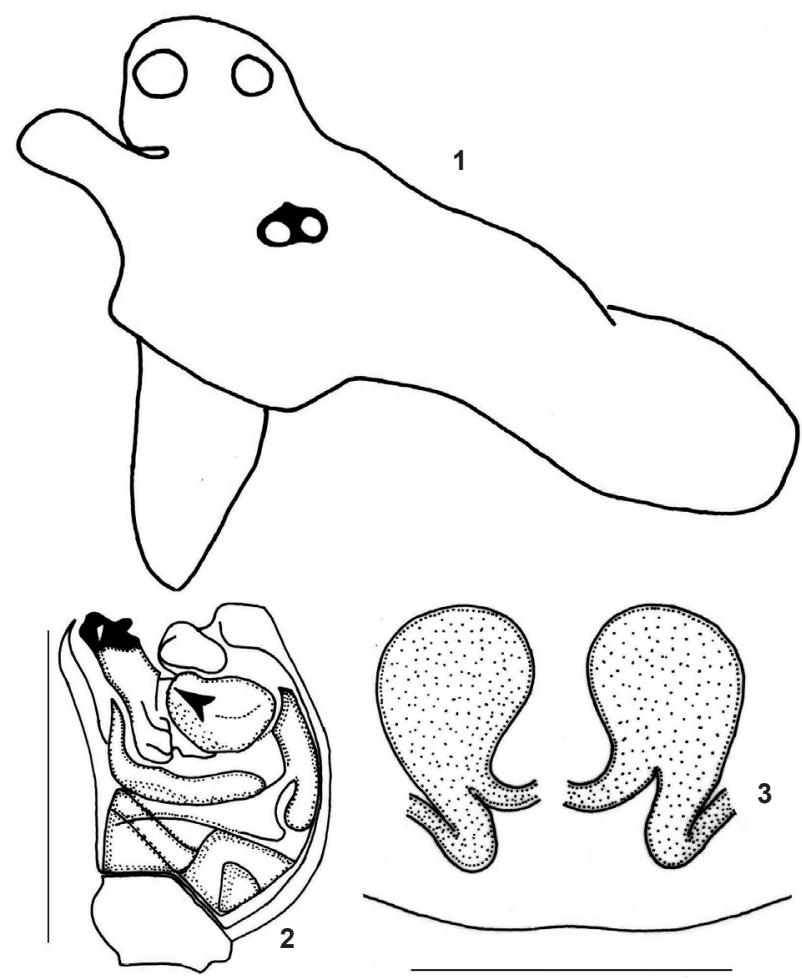

Figures 1-3. (Scale $0.5 \mathrm{~mm}) 1$ - Male carapace lateral aspect of Argyrodes nephilae; 2 - Male palp retrolateral aspect; 3 Epigynum inner aspect/dorsal view.

\section{Argyrodes argentatus O.P. -Cambridge, 1880 (Images 4-6a; Figures 4-6)}

\section{Material examined}

25.xii.2008, 1 Male (NHM.OU.SPI.3-2009), 1 Female (NHM.OU.SPI.4-2009), $18^{\circ} 35^{\prime} \mathrm{N}$ \& $84^{\circ} 15^{\prime} \mathrm{E}$, along the bund of Dali Cheruvu, Tekkali mandal, Srikakulam District, Andhra Pradesh, coll. S.M. Maqsood Javed; 04.i.2009, 1 Male (NHM.OU.SPI.5-2009), 1 Female (NHM.OU.SPI.6-2009), $17^{\circ} 25^{\prime} \mathrm{N}$ \& 78031'E, Osmania University Campus, Hyderabad, Andhra Pradesh, coll. C. Srinivasulu.

\section{Description}

Male: Carapace dark brown. Sternum is light brown. Legs are light to almost white, darker at joints. Abdomen is completely studded with silver above with a narrow dark median line on dorsal region and a small black spot at the tip (Image 4). Ventral and lower parts of the abdomen and sides are black with a pair of round orange spots in front of spinnerets (in live condition, but turns solid silver after fixation in $70 \%$ ethyl alcohol). Cephalic projection bearing median eyes is raised. Clypeal projection slender, extending anteriorly at a slight upward angle beyond head, narrowed in middle and expanded into a knob distally (Figure 6). Abdomen is small in size and cone-shaped. Palpal organ as shown in Figure 5.

Measurements: Total length 1.52; carapace 0.81 long, 

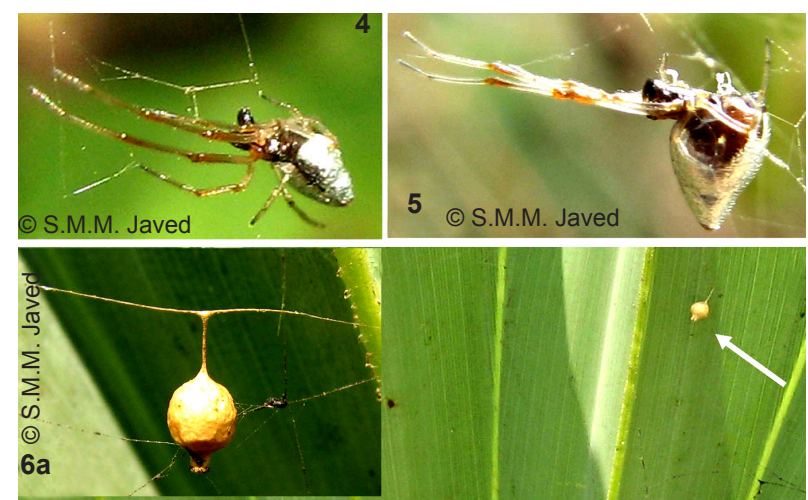

S.M.M. Javed

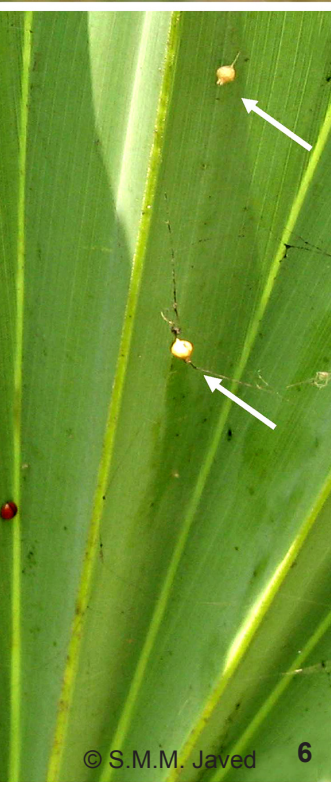

Images 4-6a. 4 - Argyrodes argentatus male (live) hanging inverted on the web; 5 - Argyrodes argentatus female (live) hanging inverted on the web; 6 \& 6a - Egg sac close view (inset) \& arrangement of egg sacs hanging inverted underside of borassus leaf (shown by arrows).

0.30 wide; abdomen 0.71 long, 0.80 wide, height 1.02 .

Leg formula: 1,4,2,3; leg lengths: I,II,III,IV (2.49, 1.77, $1.2,1.80)$.

\section{Female}

Similar to males in coloration, but does not possess cephalic projection. They are comparatively larger in size than males (Image 5). Epigynum as shown in Figure 6.

Measurements: Total length 1.24; carapace 0.91 long, 0.50 wide; abdomen 0.33 long, 1.49 wide, height 1.84 .

Leg formula: 1,4,2,3; leg lengths: I,II,III,IV (3.68, 2.62, $1.80,2.66)$.

\section{Distribution}

Mexico, Lower Amazons, East Indies, Ceylon (Sri Lanka) and Madagascar (Cambridge 1880), Tharrawaddy (in Burma), Ceylon (Sri Lanka), India, Madagascar and South America (Thorell 1895) and China (Song et al. 2001). But locality details of specimens collected from India is not provided by Thorell (1890). According to Platnick (2009) it is distributed in China, East Indies and Hawaii.

\section{Microhabitat}

We recorded the specimens of Argyrodes argentatus from the webs of Araneidae spiders Argiope anasuja,

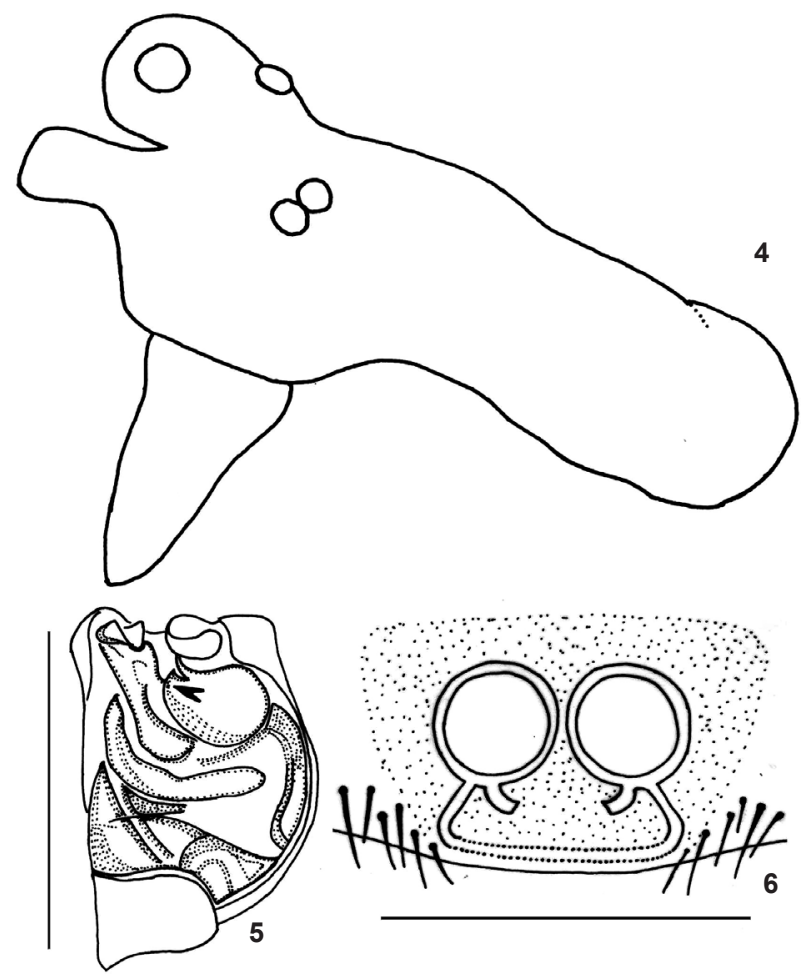

Figures 4-6. (Scale 0.5mm) 4 - Male carapace lateral aspect of Argyrodes argentatus; 5 - Male palp retrolateral aspect; 6 - Epigynum inner aspect/dorsal view.

Cyrtophora citricola and Thelacantha brevispina on Chromolaena odorata and Borassus flabillifer near the sea coast. The Osmania University Campus specimens were recorded on the web of Argiope anasuja on an exotic ornamental plant.

\section{Argyrodes falvescens O.P. -Cambridge, 1880 (Images 7 \& 7a; Figures 7-9)}

\section{Material examined}

25.11.2009, 1 Male (NHM.OU.SPI.7-2009), 1 Female (NHM.OU.SPI.8-2009), $18^{\circ} 16^{\prime} \mathrm{N} \& 83^{\circ} 02^{\prime} \mathrm{E}$, along the bank of Gostani River near Borra Caves, Ananthagiri mandal, Vishakapatnam District, Andhra Pradesh, coll. S.M. Maqsood Javed.

\section{Description}

Male: Carapace reddish-brown (orange in life). Legs brown to dark brown (black in life), the fourth tarsus often yellow and the femora sometimes with yellow annulations. Abdomen is pale yellow (orange in life) with several pairs of silver spots on the dorsal and lateral surfaces, and with two black spots on the top and at the posterior end (Tanikawa et al. 1996). Clypeal projection slender, extending anteriorly, but slightly equal or shorter than head (Figure 7). Palpal organ as shown in Figure 8.

Measurements: Total length 2.12; carapace 0.92 long, 0.40 wide; abdomen 1.08 long, 0.90 wide, height 1.12 . 


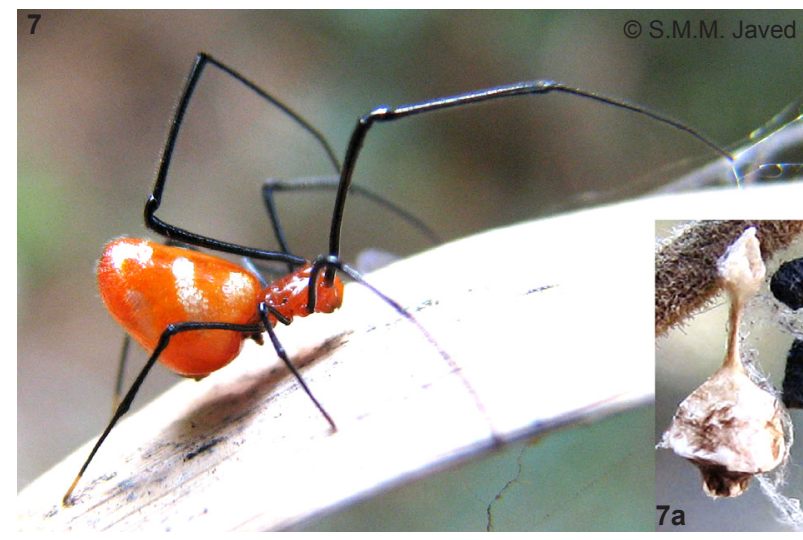

Images 7-7a - Argyrodes falvescens Female lateral aspect (live) and lateral aspect of Egg sac hanging inverted (Inset).

Leg formula: 1,2,4,3; leg lengths: I,II,III,IV (4.59, 3.10, $1.30,2.50)$.

\section{Female}

Similar to males in coloration, but does not possess cephalic projection. They are comparatively larger in size than males (Image 7). Epigynum as shown in Figure 9.

Measurements: Total length 5.69; carapace 2.10 long, 1.11 wide; abdomen 3.59 long, 2.10 wide, height 4.97 .

Leg formula: 1,2,4,3; leg lengths: I,II,III,IV (10.12, $6.72,4.21,6.29)$.

\section{Distribution}

Japan (Nansei Islands), China (Zhu \& Song 1991), Sumatra, Indonesia (Thorell 1890), Sri Lanka (O.P.Cambridge 1880), Malaysia and Papua New Guinea and Korea (Namkung 2003). According to Platnick (2009) it is distributed from Sri Lanka to Japan and New Guinea.

\section{Micro habitat}

We recorded the specimens of Argyrodes falvescens on the web of Araneidae spider Argiope anasuja on Bambusa arundinacea on the bank of river Gosthani.

\section{Discussion and Conclusion}

Argyrodes nephilae, Argyrodes argentatus and Argyrodes falvescens species are kleptoparasites and hang upside-down in the webs of their hosts (usually other araneid spiders) or on webs of their own. Their front pairs of legs are held folded close to the body. They are usually inconspicuous, resembling seeds, pieces of bark, or lichen attached to the web. When disturbed they jump, usually sideways, and drop, leaving a line attached to the resting place. They forage in the webs of their host spiders. Some hosts, like Cyrtophora citricola and Thelacantha brevispina, do not mind their presence and pay little attention to their activities, while Argiope anasuja reacts aggressively and on many occasions we have observed them to feed on Argyrodes. On a few occasions we have observed Argyrodes argentatus glean small insects from

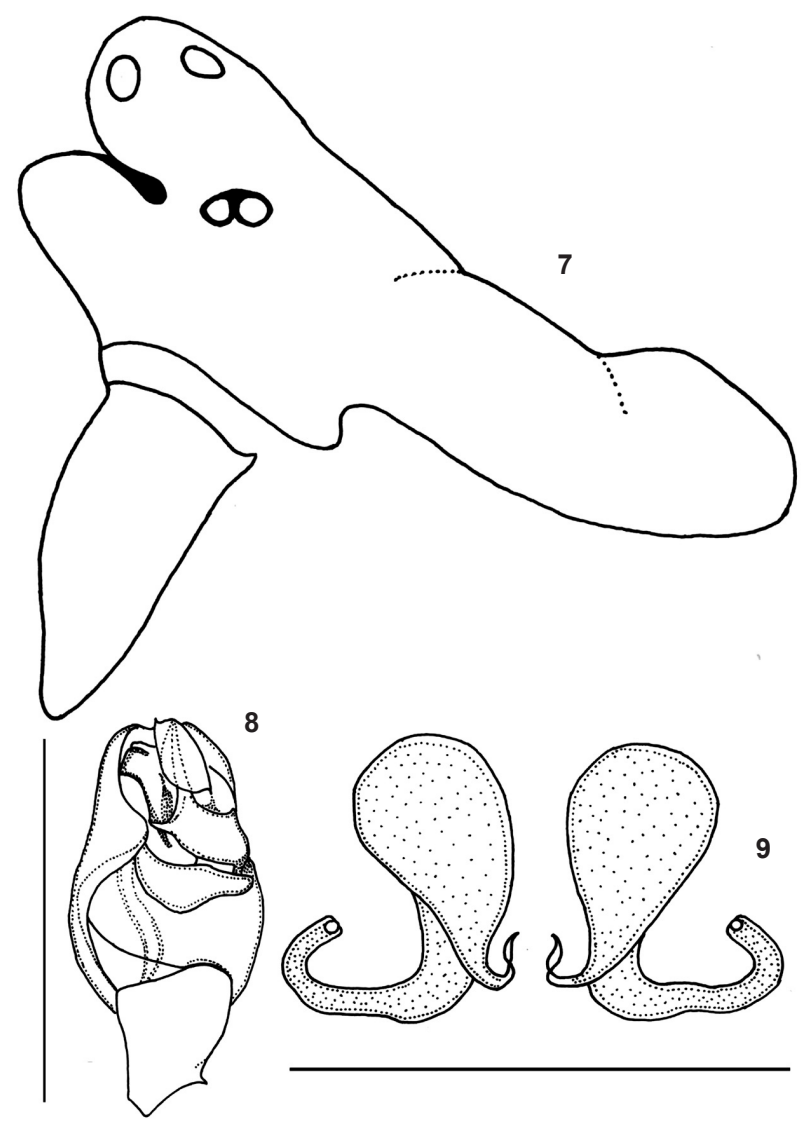

Figures 7-9. (Scale 0.5mm) 7 - Male carapace lateral aspect of Argyrodes falvescens; 8 - Male palp retrolateral aspect; 9 - Epigynum inner aspect/dorsal view.

the host web. These were sometimes eaten where found or wrapped and taken to the margin of the host's web and eaten there. These kleptoparasitic spiders are also known to remove and eat spiral catching silk of the host's web, sometimes removing large sections like in the case of Argyrodes argentatus (Alexander 2005; present study) and Argyrodes falvescens (present study), but never in case of Argyrodes nephilae. Argyrodes falvescens is most aggressive and has been reported to steal freshly captured prey items from the host and damage host webs, leading to host relocation, loss of body weight and increased juvenile mortality (Koh \& Li 2002).

All three species build a separate, small tent web away from the host web or use the abandoned portion of the host web to place their egg sac. The egg sacs of the three species are identical, being pale white to light brown in appearance and spherical with a long stalk (Image 3, 6, 6a \& 7a) about 8-10 $\mathrm{mm}$ in length (3-4 mm wide), composed of stiff yellowish-brown silk. The upper part is a cone, rounded or tapering well to a point, at which is attached a stiff white cord, by which it is fastened into its place among the crossed lines of the snare. The lower part of the basket terminates in a short projection from the middle. The egg sacks are suspended by long, stout cords. When this hanging egg sac is opened the eggs are 
seen loosely deposited in the middle of a little puff of flossy silk. The bottom of the egg sac possesses a little hole, through which the offspring comes out after hatching. We observed several egg sacs of these species.

The three species recorded by us are obligate kleptoparasites and may interact with their hosts in several ways, as a kleptoparasite stealing the host's prey, etc. In future, there is a scope to reveal several other aspects of the relationship between these species and their hosts, like host specificity, territoriality, movement, invaders among host webs of the same or of different species and others.

\section{REFERENCES}

Agnarsson, I. (2004). Morphological phylogeny of cobweb spiders and their relatives (Araneae, Araneoidea, Theridiidae). Zoological Journal of the Linnean Society, 141: 447-626 (with 111 figures).

Alexander, M.K. (2005). Behavior of web-invading spiders Argyrodes argentatus (Theridiidae) in Argiope appensa (Araneidae) host webs in Guam. The Journal of Arachnology 33: 1-6.

Cambridge, O.P.-. (1880). On some new and little-known spiders of the genus Argyrodes. Proceedings of the Zoological Society of London, 1880: 320-342.

Chikuni Y. (1989). Pictorial Encyclopedia of Spiders in Japan. Kaisei-sha, Tokyo, 310pp.

Exline, H. \& H.W. Levi (1962). American spiders of the genus Argyrodes (Araneae, Theridiidae). Bulletin of the Museum of Comparative Zoology 127: 75-214.

Jose, K.S. (2005). A faunistic survey of Spiders (Araneae: Arachnida) in Kerala, India. PhD Thesis. Mahatma Gandhi University, Kottayam, Kerala, India, 407pp.
Koh, T.H. \& D. Li (2002). Population characteristics of a kleptoparasitic spider Argyrodes flavescens (Araenae: Theridiidae) and its impact on a host spider Nephila pilipes (Araneae: Tetragnathidae) from Singapore. The Raffles Bulletin of Zoology 50(1): 153-160.

Larcher, S.R. \& D.H. Wise (1985). Experimental studies of the interactions between a web-invading spider and two host species. The Journal of Arachnology 13: 43-59.

Namkung, J. (2003). The Spiders of Korea - 2nd edition. KyoHak Publication Company, Seoul, 648pp.

Platnick, N.I. (2009). The World Spider Catalog, Version 9.5, American Museum of Natural History. Website: < http://research.amnh.org/entomology/spiders/catalog/ THERIDIIDAE.html> (Accessed on $11^{\text {th }}$ January 2010).

Siliwal, M. \& S. Molur (2007). Checklist of spiders (Arachnida: Araneae) of South Asia including the 2006 update of Indian spider checklist. Zoos' Print Journal 22(2): 2551-2597 (with web supplement).

Song, D.X., M.S. Zhu \& J. Chen (2001). The Fauna of Hebei, China: Araneae. Hebei Science Technology Publication House, 510pp.

Tanikawa, A., T. Chida \& Ken-Ichi Kumada (1996). New Records of Argyrodes flavescens (Araneae: Theridiidae) from Japan. Acta arachnologica 45(1): 47-52.

Thorell, T. (1890). Studi sui Ragni Malesi e Papuani. Part IV, 1. Annali del Museo Civico di Storia Naturale di Genova 2(8): 1-419.

Thorell, T. (1895). Descriptive Catalogue of the Spiders of Burma based upon the collection made by Eugene W. Oates and preserved in the British Museum. London, UK., 406pp.

Tikader, B.K. (1966). Spider fauna of Sikkim. Records of the Zoological Survey of India 64(1-4): 1-258

Wise, D.H. (1982). Predation by a commensal spider Argyrodes trigonum upon its host: An experimental study. The Journal of Arachnology 10: 111-116.

Zhu, M.S. \& D.X. Song (1991). Notes on the genus Argyrodes from China (Araneae: Theridiidae). Journal of Hebei Pedagogic Collection, Natural Science Edition 91(4): 130146. 